\title{
RNA Trans-Splicing in Normal and Cancer Cells
}

\section{Hui Li*}

Department of Pathology, University of Virginia, Charlottesville, VA

\section{Introduction}

Recent studies of regulatory RNA, such as microRNA [1] and piRNA [2] and long non-coding RNAs (IncRNAs) [3] have redirected attention back to RNA. Once thought of as an informational macromolecule that merely carries messages from the genome to the proteome, RNA is becoming increasingly appreciated as a master regulatory molecule in its own right. So, what about genetic information flow? Does DNA sequence dictate all mRNA transcripts? Are 20,000 30,000 genes enough to explain the complexity of human cells? Alternative splicing, through which segments of a gene are arranged in multiple ways in a collinear fashion, can expand the functional genome several fold. However, our recent work suggests another mechanism that, in principle, can exponentially increase the functional genetic repertoire in humans. In this mechanism called "trans-splicing", two independent gene transcripts are spliced together to create a new fusion [4,5]. Because there is no collinearity requirement for trans-splicing, the total number of possible transcripts greatly exceeds that of alternative splicing [6].

Trans-splicing is common in lower species, such as trypanosomes and nematodes. In these organisms, 5' leader sequences are transspliced to most (in nematodes) or all (in trypanosomes) transcripts and analogous to mammalian cells, provide an alternative means of capping mRNAs. However, this kind of trans-splicing does not expand genetic information. Only a few isolated examples of true intergenic RNA trans-splicing have been reported in mammals [7-11]. Because these previous examples of trans-splicing are few in number, their products low in abundance, and no function has been ascribed to them, transsplicing in mammals has been regarded as non-specific due to the sloppiness of spliceosomes [12].

Serendipitously, we found a functional trans-splicing in human uterine cells. The fusion transcript contains 3' JJAZ1 (Suz12), a key member of Polycomb group genes (PcG), and 5' of another gene, JAZF1. The fusion product JAZF1-JJAZ1 seems to still retains the binding capability of normal JJAZ1 to another Polycomb Complex 2 member EZH2. In addition, it markedly inhibits apoptosis in HEK293 cells [4]. The JAZF1-JJAZ1 fusion transcript is the first example of a trans-spliced product that is abundant and functional. Notably, the fusion RNA and protein products of this trans-splicing event in normal uterine cells are identical to the products made by DNA translocation in some uterine tumors.

Chimeric gene fusion is common in neoplasia. The fusion products have been thought to be the result of chromosomal rearrangement and therefore a unique feature of neoplasia. However, the finding of an identical fusion product in normal cells as in cancer argues against this dogma [13]. It is highly likely that tumors "short-circuit" a regulatory mechanism that is "cautiously" used by normal cells. Created by DNA rearrangements in human tumors, neoplastic gene fusions lead to constitutive production of chimeric RNAs and proteins that are normally produced in a regulated fashion during a particular stage of cell growth and differentiation. On the other hand, because the end product of trans-splicing has oncogenic activity, mis-regulated transsplicing machinery could conceivably lead to cancer [14].

JAZF1-JJAZ1 is a good model in that the trans-spliced fusion product is functional in normal uterine cells, presumably protecting some population of uterine precursor cells to survive the menses stress and subsequently re-grow the whole functional layer. However, it is so far the only such example. In order to generalize the phenomena and provide insights into the mechanism of trans-splicing, there is an urgent need to know how broad this mechanism is used in human cells.

Trans-splicing studies will have broad impact not only on the basic understanding of cancer, but also on the general knowledge of molecular and cellular biology: (1) Trans-splicing, together with alternative splicing, intron retention, gene read-through and other possible unidentified mechanisms can expand the repertoire of functions that could be mediated by the finite number of genes within mammalian genomes; (2) Defects in the process of trans-splicing may account for various pathological conditions, especially cancer, given the large number of gene fusions already discovered in tumors. "Jammed up" or hyperactive trans-splicing could lead to cancer; (3) It is very intriguing that RNA trans-splicing in normal cells can generate the exact same product as DNA translocation in tumors. It is highly conceivable that the chimeric RNA from trans-splicing could also serve as a mediator for DNA translocation. There has been one such example in which RNA served as a 'blueprint' for DNA rearrangement in ciliates [15].

The study of trans-splicing will also have significant clinical impact. Manipulation of trans-splicing or its products may have therapeutic benefits. At the same time, gene fusion products often, if not always, have some causal roles in carcinogenesis, and are thought to be "uniquely" confined to cancer cells. They are believed to be the ideal diagnostic markers and rational therapeutic targets. Widespread trans-splicing in normal cells will raise concerns for false positive cancer diagnoses with current diagnostic methods based solely on RT-PCR detection of chimeric RNA transcripts, as well as of potential side effects in normal tissues caused by therapies targeting these chimeric products.

\section{Reference}

1. Bartel DP (2009) MicroRNAs: target recognition and regulatory functions. Cell 136: $215-233$

2. Siomi MC, Sato K, Pezic D, Aravin AA (2011) PIWI-interacting small RNAs: the vanguard of genome defence. Nat Rev Mol Cell Biol 12: 246-258.

3. Rinn JL, Chang HY (2012) Genome regulation by long noncoding RNAs. Annu Rev Biochem 81: 145-166.

4. Li H, Ma X, Wang J, Koontz J, Nucci M, et al. (2007) Effects of rearrangement and allelic exclusion of JJAZ1/SUZ12 on cell proliferation and survival. Proc Natl Acad Sci U S A 104: 20001-20006.

*Corresponding author: Hui Li, Department of Pathology, University of Virginia, Charlottesville, VA, E-mail: HI9r@virginia.edu

Received August 20, 2013; Accepted August 21, 2013; Published August 27 2013

Citation: Hui Li (2013) RNA Trans-Splicing in Normal and Cancer Cells. J Biomo Res Ther 2: e112. doi:10.4172/2167-7956.1000e112

Copyright: ๑ 2013 Hui Li. This is an open-access article distributed under the terms of the Creative Commons Attribution License, which permits unrestricted use, distribution, and reproduction in any medium, provided the original author and source are credited. 
5. Li H, Wang J, Mor G, Sklar J (2008) A neoplastic gene fusion mimics transsplicing of RNAs in normal human cells. Science 321: 1357-1361.

6. Gingeras TR (2009) Implications of chimaeric non-co-linear transcripts. Nature 461: 206-211.

7. Caudevilla C, Serra D, Miliar A, Codony C, Asins G, et al. (1998) Natural transsplicing in carnitine octanoyltransferase pre-mRNAs in rat liver. Proc Natl Acad Sci U S A 95: 12185-12190.

8. Frantz SA, Thiara AS, Lodwick D, Leong Ng, Eperon IC, et al. (1999) Exon repetition in mRNA. Proc Natl Acad Sci USA 96: 5400-5405.

9. Flouriot G, Brand H, Seraphin B, Gannon F (2002) Natural trans-spliced mRNAs are generated from the human estrogen receptor-alpha (hER alpha) gene. J Biol Chem 277: 26244-26251.

10. Jehan Z, Vallinayagam S, Tiwari S, Pradhan S, Singh L, et al. (2007) Novel noncoding RNA from human $Y$ distal heterochromatic block (Yq12) generates testis-specific chimeric CDC2L2. Genome Res 17: 433-440.
11. Zhang C, Xie Y, Martignetti JA, Yeo TT, Massa SM, et al. (2003) A candidate chimeric mammalian mRNA transcript is derived from distinct chromosomes and is associated with nonconsensus splice junction motifs. DNA Cell Biol 22 303-315.

12. Maniatis T, Tasic B (2002) Alternative pre-mRNA splicing and proteome expansion in metazoans. Nature 418: 236-243.

13. Rowley JD, Blumenthal T (2008) Medicine. The cart before the horse. Science 321: $1302-1304$

14. Li H, Wang J, Ma X, Sklar J (2009) Gene fusions and RNA trans-splicing in normal and neoplastic human cells. Cell Cycle 8: 218-222.

15. Nowacki M, Vijayan V, Zhou Y, Schotanus K, Doak TG, et al. (2008) RNAmediated epigenetic programming of a genome-rearrangement pathway. Nature 451: 153-158. 